\title{
PET/MRI and PET/CT: is there room for both at the top of the food chain?
}

\author{
Torsten Kuwert $^{1} \cdot$ Philipp Ritt $^{1}$
}

Published online: 19 November 2015

(C) Springer-Verlag Berlin Heidelberg 2015

In this issue of the journal, Vrachimis and colleagues demonstrate that positron emission tomography combined with Xray computed tomography (PET/CT) outperforms PET combined with magnetic resonance imaging (PET/MRI) in restaging radioiodine-negative patients with biochemical relapse of differentiated thyroid carcinoma [1]. This comes as a surprise, at least to the uninitiated: In a world predominantly driven by material considerations, common sense would presume that diagnostic accuracy correlates with costs, and PET/ MRI indeed "outperforms" PET considerably with regard to its demands on resources spent on acquisition and operation.

A closer look at the data proffered by Vrachimis et al. reveals that the poorer performance of PET/MRI compared to $\mathrm{PET} / \mathrm{CT}$ for this indication resides in its shortcomings in the ability to diagnose pulmonary metastases, a frequent occurrence in progressive thyroid carcinoma. MRI aficionados will argue that this problem may be overcome by using MRI sequences dedicated to lung imaging. This contingent may ultimately be correct, but such arguments are purely speculative at the moment, as empirical proof for the case of PET/MRI is lacking.

A comprehensive review on the evidence reporting the use of PET/MRI in a clinical setting is beyond the scope of this editorial. However, a short appraisal of the hitherto published literature comparing the utility of PET/MRI and PET/CT can be attempted: At the time of this writing, 166 papers featuring

This Editorial Commentary refers to the article http://dx.doi.org/10.1007/ s00259-015-3195-2.

Torsten Kuwert

torsten.kuwert@uk-erlangen.de

1 Clinic of Nuclear Medicine, University Hospital Erlangen, Ulmenweg 18, 91054 Erlangen, Germany the keyword combination "PET/MR PET/CT" currently reside in the Web of Science (ISI) Internet library. Of these, roughly 22 are original articles comparing the diagnostic performance of these two hybrid imaging modalities in oncology. Six report data from mixed groups of patients [2-7], with five finding an equivalence of diagnostic performance of the two hybrid imaging technologies and one a slight superiority of PET/MRI over PET/CT with regard to influence on further clinical management. None deals with thyroid cancer directly, allowing us to consider the new publication under discussion by Vrachimis et al. the first to study this neoplastic entity specifically. However, the utility of PET/MRI and PET/CT to detect and characterize small pulmonary nodules more generally has been previously investigated in three papers, with the data tipping the scales in favour of PET/CT [8-10]. The remaining 13 publications report some evidence that PET/ MRI is superior to PET/CT for characterizing primary tumours, e.g. primary bone tumours [11-13] or oesophageal carcinoma [14], but do not demonstrate significant advantages of whole-body MRI over whole-body PET/CT for N or M staging [15-24].

The introduction of PET/MRI was heralded as a technological breakthrough, and many expected a subsequent clinical revolution, with the newer modality vying to supersede $\mathrm{PET} / \mathrm{CT}$ atop the diagnostic food chain just as the Burmese python is supplanting the American alligator in the Florida Everglades. However, none of the above-mentioned papers offers a definitive answer as to whether or not integrated and simultaneous PET/MR imaging is clinically more accurate than sequentially performed whole-body PET/CT and MRI dedicated to one body region registered in retrospect.

In this regard, the situation is much different from the one nearly two decades ago when PET/CT was introduced and its diagnostic performance compared to that of stand-alone PET. The dramatic success of PET/CT was not only due to its 
diagnostic superiority over PET, but also to the considerable shortening of data acquisition possible via substitution of lengthy transmission scans needed for PET attenuation correction with CT. In the case of PET/MRI, data acquisition is actually prolonged relative to the current standard, thus reducing patient throughput - a highly economically relevant variable. It is possible that, when considering the clinical workflow from start to finish that a particular patient must undergo, a PET/MR scan may be more time-efficient than consecutive PET and MR examinations. The reality, however, of imaging institutions having to live as separate profit centres on their own budgets often overrules these holistic considerations.

Clinical use of PET/MRI was thoroughly discussed at a workshop held this year in Tübingen, Germany [25]. While it was generally acknowledged that PET/MRI is not currently viable as a complete replacement for PET/CT, calls were made for its use in CT-guided PET/MR examinations of fields of view limited to potential pathology, ideally in diseases that receive obligatorily diagnostic workup by MRI. However, in oncology, the number of overlapping clinical indications for fluorodeoxyglucose (FDG) PET and MR imaging is quite limited, as stated by Weber in a recent editorial in the Journal of Nuclear Medicine [26]. Nevertheless, new tracers such as the radioactively labelled amino acids used for diagnosis of gliomas or PET radiopharmaceuticals tracing the expression of prostate-specific membrane antigen (PSMA) in prostate carcinomas potentially offer a better platform for PET/MR hybrid imaging, as emerging evidence on PET imaging in prostate cancer already indicates (see also $[25,26])$.

In addition to new tracers, multiparametric imaging could have implications for PET/MR imaging in oncology in the future. This concept is particularly attractive for the new hybrid modality, as MR is not only capable of imaging morphology, but also physiological and biochemical variables. Two recent publications have already attempted to elucidate the potential of multiparametric PET/MRI by comparing abnormalities in MR diffusion imaging to the magnitude of FDG uptake in neoplastic lesions [27, 28]. Within this paradigm, PET/MRI is expected to deliver a more integrated view of disease processes than PET/CT and, thus, ultimately provide diagnostically valuable information inaccessible using traditional PET/CT.

Regardless of the growing pains it is currently experiencing, PET/MRI is one of the most active research areas in our field, as evidenced by the 406 ISI listed research articles published between January 2013 and 21 October 2015 that study its impact. It is to be expected that these intensive scientific efforts will rapidly help us understand how PET/MRI can be used to the benefit of individual patients and should point towards a well-suited role for the modality in the clinical routine. The scenario evolving thus evokes not so much the fight for survival taking place between pythons and alligators in the
Everglades, but rather the coexistence of lions and cheetahs in the African Savannah, whose non-overlapping hunting routines allow them to share the role of apex predator.

Acknowledgments The authors gratefully acknowledge the language review of James C. Sanders of this manuscript as well as the fruitful discussions with him on various topics of multimodal imaging. Professor Peter Bartenstein called the first author's attention to concerns of reptilian wildlife in Florida. The Erlangen Clinic of Nuclear Medicine has an ongoing scientific cooperation with Siemens with regard to the development and validation of SPECT/CT technology. The cooperation of this clinic with Siemens in the field of PET/MRI ended in 2014.

\section{References}

1. Vrachimis A, Burg MC, Wenning C, Allkemper T, Weckesser M, Schäfers M, et al. [18F]FDG PET/CT outperforms [18F]FDG PET/ MRI in differentiated thyroid cancer. Eur J Nucl Med Mol Imaging 2015. doi:10.1007/s00259-015-3195-2.

2. Drzezga A, Souvatzoglou M, Eiber M, Beer AJ, Fürst S, MartinezMöller A, et al. First clinical experience with integrated whole-body PET/MR: comparison to PET/CT in patients with oncologic diagnoses. J Nucl Med 2012;53(6):845-55. doi:10.2967/jnumed.111. 098608.

3. Wiesmüller M, Quick HH, Navalpakkam B, Lell MM, Uder M, Ritt $\mathrm{P}$, et al. Comparison of lesion detection and quantitation of tracer uptake between PET from a simultaneously acquiring whole-body PET/MR hybrid scanner and PET from PET/CT. Eur J Nucl Med Mol Imaging 2013;40(1):12-21. doi:10.1007/s00259-012-2249-y.

4. Huellner MW, Appenzeller P, Kuhn FP, Husmann L, Pietsch CM, Burger IA, et al. Whole-body nonenhanced PET/MR versus PET/ $\mathrm{CT}$ in the staging and restaging of cancers: preliminary observations. Radiology 2014;273(3):859-69. doi:10.1148/radiol. 14140090.

5. Catalano OA, Rosen BR, Sahani DV, Hahn PF, Guimaraes AR, Vangel MG, et al. Clinical impact of PET/MR imaging in patients with cancer undergoing same-day PET/CT: initial experience in 134 patients-a hypothesis-generating exploratory study. Radiology 2013;269(3):857-69. doi:10.1148/radiol.13131306.

6. Schäfer JF, Gatidis S, Schmidt H, Gückel B, Bezrukov I, Pfannenberg CA, et al. Simultaneous whole-body PET/MR imaging in comparison to PET/CT in pediatric oncology: initial results. Radiology 2014;273(1):220-31. doi:10.1148/radiol.14131732.

7. Al-Nabhani KZ, Syed R, Michopoulou S, Alkalbani J, Afaq A, Panagiotidis E, et al. Qualitative and quantitative comparison of PET/CT and PET/MR imaging in clinical practice. J Nucl Med 2014;55(1):88-94. doi:10.2967/jnumed.113.123547.

8. Rauscher I, Eiber M, Fürst S, Souvatzoglou M, Nekolla SG, Ziegler SI, et al. PET/MR imaging in the detection and characterization of pulmonary lesions: technical and diagnostic evaluation in comparison to PET/CT. J Nucl Med 2014;55(5):724-9. doi:10.2967/ jnumed.113.129247.

9. Stolzmann P, Veit-Haibach P, Chuck N, Rossi C, Frauenfelder T, Alkadhi $\mathrm{H}$, et al. Detection rate, location, and size of pulmonary nodules in trimodality PET/CT-MR: comparison of low-dose CT and Dixon-based MR imaging. Invest Radiol 2013;48(5):241-6. doi:10.1097/RLI.0b013e31826f2de9.

10. Chandarana H, Heacock L, Rakheja R, DeMello LR, Bonavita J, Block TK, et al. Pulmonary nodules in patients with primary malignancy: comparison of hybrid PET/MR and PET/CT imaging. Radiology 2013;268(3):874-81. doi:10.1148/radiol.13130620. 
11. Eiber M, Takei T, Souvatzoglou M, Mayerhoefer ME, Fürst S, Gaertner FC, et al. Performance of whole-body integrated 18FFDG PET/MR in comparison to PET/CT for evaluation of malignant bone lesions. J Nucl Med 2014;55(2):191-7. doi:10.2967/ jnumed.113.123646.

12. Catalano OA, Nicolai E, Rosen BR, Luongo A, Catalano M, Iannace $\mathrm{C}$, et al. Comparison of CE-FDG-PET/CT with CE-FDG$\mathrm{PET} / \mathrm{MR}$ in the evaluation of osseous metastases in breast cancer patients. Br J Cancer 2015;112(9):1452-60. doi:10.1038/bjc.2015. 112.

13. Samarin A, Hüllner M, Queiroz MA, Stolzmann P, Burger IA, von Schulthess G, et al. 18F-FDG-PET/MR increases diagnostic confidence in detection of bone metastases compared with 18F-FDGPET/CT. Nucl Med Commun 2015;36(12):1165-73. doi:10.1097/ mnm.0000000000000387.

14. Lee G, Hoseok I, Kim SJ, Jeong YJ, Kim IJ, Pak K, et al. Clinical implication of PET/MR imaging in preoperative esophageal cancer staging: comparison with PET/CT, endoscopic ultrasonography, and CT. J Nucl Med 2014;55(8):1242-7. doi:10.2967/jnumed. 114.138974.

15. Varoquaux A, Rager O, Poncet A, Delattre BM, Ratib O, Becker $\mathrm{CD}$, et al. Detection and quantification of focal uptake in head and neck tumours: (18)F-FDG PET/MR versus PET/CT. Eur J Nucl Med Mol Imaging 2014;41(3):462-75. doi:10.1007/s00259-0132580-y.

16. Kuhn FP, Hüllner M, Mader CE, Kastrinidis N, Huber GF, von Schulthess GK, et al. Contrast-enhanced PET/MR imaging versus contrast-enhanced PET/CT in head and neck cancer: how much MR information is needed? J Nucl Med 2014;55(4):551-8. doi: 10.2967/jnumed.113.125443.

17. Partovi S, Kohan A, Vercher-Conejero JL, Rubbert C, Margevicius $\mathrm{S}$, Schluchter MD, et al. Qualitative and quantitative performance of 18F-FDG-PET/MRI versus 18F-FDG-PET/CT in patients with head and neck cancer. AJNR Am J Neuroradiol 2014;35(10):19705. doi:10.3174/ajnr.A3993.

18. Schaarschmidt BM, Heusch P, Buchbender C, Ruhlmann M, Bergmann C, Ruhlmann V, et al. Locoregional tumour evaluation of squamous cell carcinoma in the head and neck area: a comparison between MRI, PET/CT and integrated PET/MRI. Eur J Nucl Med Mol Imaging 2015. doi:10.1007/s00259-015-3145-z.

19. Heusch P, Buchbender C, Köhler J, Nensa F, Gauler T, Gomez B, et al. Thoracic staging in lung cancer: prospective comparison of
18F-FDG PET/MR imaging and 18F-FDG PET/CT. J Nucl Med 2014;55(3):373-8. doi:10.2967/jnumed.113.129825.

20. Ohno Y, Koyama H, Yoshikawa T, Takenaka D, Seki S, Yui M, et al. Three-way comparison of whole-body MR, coregistered whole-body FDG PET/MR, and integrated whole-body FDG PET/CT imaging: TNM and stage assessment capability for nonsmall cell lung cancer patients. Radiology 2015;275(3):849-61. doi:10.1148/radiol.14140936.

21. Huellner MW, Barbosa FG, Husmann L, Pietsch CM, Mader CE, Burger IA, et al. TNM staging of NSCLC: comparison of PET/MR and PET/CT. J Nucl Med 2015. doi:10.2967/jnumed.115.162040.

22. Boss A, Bisdas S, Kolb A, Hofmann M, Ernemann U, Claussen $\mathrm{CD}$, et al. Hybrid PET/MRI of intracranial masses: initial experiences and comparison to PET/CT. J Nucl Med 2010;51(8):1198205. doi:10.2967/jnumed.110.074773.

23. Souvatzoglou M, Eiber M, Takei T, Fürst S, Maurer T, Gaertner F, et al. Comparison of integrated whole-body [11]C-choline PET/MR with PET/CT in patients with prostate cancer. Eur J Nucl Med Mol Imaging 2013;40(10):1486-99. doi:10.1007/s00259-013-2467-y.

24. Afshar-Oromieh A, Haberkorn U, Schlemmer HP, Fenchel M, Eder $\mathrm{M}$, Eisenhut M, et al. Comparison of PET/CT and PET/MRI hybrid systems using a 68Ga-labelled PSMA ligand for the diagnosis of recurrent prostate cancer: initial experience. Eur J Nucl Med Mol Imaging 2014;41(5):887-97. doi:10.1007/s00259-013-2660-z.

25. Bailey DL, Pichler BJ, Gückel B, Barthel H, Beer AJ, Bremerich J, et al. Combined PET/MRI: multi-modality multi-parametric imaging is here : Summary Report of the 4th International Workshop on PET/ MR Imaging; February 23-27, 2015, Tübingen, Germany. Mol Imaging Biol 2015;17(5):595-608. doi:10.1007/s11307-015-0886-9.

26. Weber WA. PET/MR imaging: a critical appraisal. J Nucl Med 2014;55(2):56S-8S. doi:10.2967/jnumed.113.129270.

27. Grueneisen J, Beiderwellen K, Heusch P, Buderath P, Aktas B, Gratz M, et al. Correlation of standardized uptake value and apparent diffusion coefficient in integrated whole-body PET/MRI of primary and recurrent cervical cancer. PLoS One 2014;9(5):e96751. doi:10.1371/journal.pone.0096751.

28. Schwenzer NF, Schmidt H, Gatidis S, Brendle C, Müller M, Königsrainer I, et al. Measurement of apparent diffusion coefficient with simultaneous MR/positron emission tomography in patients with peritoneal carcinomatosis: comparison with 18F-FDG-PET. J Magn Reson Imaging 2014;40(5):1121-8. doi:10.1002/jmri. 24497. 